\title{
Ecological and Economic Aspects of the Spread of Helminthiasis in the Coal Region on the Example of Kuzbass
}

\author{
Lubov Nacheva ${ }^{1}$, Irina Kudryashova ${ }^{1,{ }^{*},}$ Ludmila Gukina ${ }^{1}$, and Natalia Zakharova ${ }^{2}$ \\ ${ }^{1}$ Kemerovo State Medical University, Kemerovo, 650029, Voroshilova St., 22A, Kemerovo, Russia \\ ${ }^{2}$ Plekhanov Russian University of Economics, 117997, Stremyanny pereulok, 36, Moscow, Russia
}

\begin{abstract}
The article deals with the ecological and economic aspects of the spread of helminthiasis in the coal region on the example of the Kemerovo region - Kuzbass. The authors note that the dominant component of environmental damage in coal-mining regions includes not only the industrial development, but also the negative impact of human activity as an anthropogenic factor of the biosystem. Based on the integrative approach of interaction between medicine, economics, and ecology, the authors developed and proposed practical measures to reduce the spread of helminthiasis in Kuzbass, which can not only effectively solve this problem, but also become the basic concept of the modern style of ecological thinking on a global scale. The paper proves the thesis that for the effective functioning of subjects of the Russian Federation with a single-industry focus, such as Kuzbass, it is necessary to form an ecological and economic mechanism that ensures the sustainable development of mining regions of the Russian Federation in changing external and internal conditions that determine the functioning of not only the mineral resource complex of mining regions, but also their socioeconomic development.
\end{abstract}

\section{Introduction}

In the XXI century, there is an active study of various issues related to the economic mechanism of environmental protection as a way to solve environmental problems in the region $[1,2,3]$. In addition, the search for opportunities to restore the ecology of the Kemerovo region, develop the processes of reconstruction of natural systems and eliminate the consequences of past environmental damage should be identified as soon as possible [4].

In modern conditions, despite the enormous achievements in the field of scientific and technological progress, the production technologies are still far from the status of "wastefree" natural processes. Industry, transport, and energy create a huge amount of emissions and waste, which for the most part remain unprocessed. Secondary products of enterprises activity cause material damage to the state, which, according to incomplete data, is quite

* Corresponding author: kudrina2007@mail.ru 
large. At the same time, the views of a number of scientists about the dominant consequences of environmental damage from the functioning of industrial enterprises or the results of human and biosphere activity remain very controversial.

All these issues are sure to be relevant and need solutions, but there is no denying that the primary basis of all environmental problems in Kuzbass is the existence of singleindustry towns with a functioning coal mining industry. Besides, it is necessary to pay special attention to the regional expansion of healthcare as a strategically important sector, which, in our opinion, sets the basic demographic, social and economic patterns of society, because it corresponds to the main task of providing health care and a decent quality of life. Often in the health care system of Kuzbass the modern tools of reengineering of business processes, such as franchising, outsourcing, and outstaffing, to leverage financial resources to the region are used. But the incentive motive is still a business interest, ecology as well as reducing the detection of helminthiasis being neglected. We believe that any "leasing" implies temporality and violates the stability of the system. In this case, it is extremely important to form a dynamic balance in the system of regional health care functioning, not only for the provision of high-quality medical care, but also for its better organization and further effective development taking into account the optimization of the main environmental and economic indicators and features of the coal-producing region. In addition, there are independent problems of ensuring human rights to a favorable environment [5]. We believe that the interaction of society and the life environment is considered primary for solving economic aspects only. Proposals and solutions to problems related to ensuring a favorable environment for residents are not sufficiently expressed, and the recognition of the fact that environmental protection is necessary not only for maintaining human well-being, but also for the implementation of their fundamental rights, including the right to life, is not highlighted.

Current scientific and theoretical thinking, the nature and changes in the style of thinking in modern natural science determine scientific and technological progress. The development of new ideas, new systemic worldview approaches has led to the understanding of the need for a radical revision of outdated ideas and principles of parasitology, clarification and rethinking of its conceptual framework, determination of prospects and specific ways of further development [6]. It is possible to solve various economic problems using digitalization, to use modern means of communication - the Internet and "iPhone", to introduce new production technologies safe for the environment, but the issues of the spread of helminthiases - parasitic diseases of humans, and other dangerous infections remain unsolved [7,8]. When discussing environmental issues of production, we should not forget that in the coal region there is still an animal world and its populations, including humans, which change directly depending on the violation of factors of their habitat and residence. At the same time, the paradox also lies in the fact that in all these problems we see the human factor as a red line [9]. The anthropogenic impact on the environment, in which the person himself exists, depends on him. The postulate of ecologists today is interpreted as follows: "Homo sapiens must be protected from Homo faber" ("that is, the most intelligent person should be protected from the person who destroys!"). The reduction of the negative influence of human factor remains an urgent issue and is very slowly being resolved. So, what is the problem? This is exactly what we want to discuss in this article.

\section{Theory}

The aim of the research is to study the influence of anthropogenic and natural environmental factors on the spread of helminthiases in the Kuzbass coal region. 
The software materials were official reports of The Federal Service for Surveillance on Consumer Rights Protection and Human Wellbeing in the city of Kemerovo, literature sources, personal observations and research. Classical scientific methods were used: descriptive, comparative, inductive method for establishing causal relationships based on the rule of inductive research by Bacon-Mill.

These studies were conducted on the basis of a systematic approach. Therefore, each type of helminthiasis is considered as a system of interaction, and host populations are located in the system of biogeocenoses, which are caused by natural factors according to the features of the ecological and economic systems of the Kuzbass coal basin as a whole.

\section{Results and Discussion}

Objective processes, theoretical prerequisites and practical needs have made it necessary to solve environmental problems in the coal region and to include the host environment, or "symbiosphere", which is filled with parasitic and opportunistic organisms, associations of free-living generations. These tasks include the study of these systems, their structure, cause-effect relationships, dependence and interaction of their components, patterns of their formation, functioning, and evolution in order to develop a theory and methods for managing them. While population parasitology studies the relationships of individual populations with the host environment, ecological parasitology should study interpopulation relationships within a particular ecoparasitic systems and their joint interaction with the host's body and the host's own living environment (host environment). What is the reason for the spread of helminths in the Kuzbass region? Mainly, the ecological characteristics of the coal region are important, the features of which should be taken into account when solving the problems of human helminthic diseases. The Kuzbass ecosystem includes, first of all, a biotope that is determined by natural abiotic factors - mountainous and hilly landscapes, a sharply continental climate, wetlands, and waterways. Predominant part of the biotope of the Kemerovo region is represented by Kuznetsk Basin, located between Kuznetsk Alatau and The Salair Ridge, the mountains of which surround the basin, and make up almost half of the total area of the region. Therefore, the natural conditions themselves create opportunities for the spread of some helminthiases. For example, for the spread of ascariasis, the stepped construction of buildings without taking into account the requirements of The State Standard to the private sector buildings in mountainous and hilly areas (it makes up almost 50\% of the region's area!) plays an important role. And the spread of trichinella, for example, especially in the South of Kuzbass, is associated with the consumption of wild animal meat (bear meat) without sanitary testing.). In artificial reservoirs within the city limits of Kemerovo, we found infection of mollusks with larvae of the liver fluke - Fasciola hepatica, which is characteristic of the artificial reservoir - dam No. 3 in the Kirovsky district of Kemerovo [10,11]. This dam serves as a source of water for the surrounding private sector and suburban buildings. Infection with fasciola larvae is possible during swimming. It should be noted that in Kemerovo four dams are located on the territory of the Kirovsky and Rudnichny districts only, from Chernomorskaya Street to Narodnaya Street. All dams belong to the Upper Ob Basin, of which the Tom River is a tributary. (This is the Upper Ob River Basin up to the confluence of the Irtysh River).

The spread of pinworms is even simpler, since the eggs, leaving the human body after 4-6 hours, become invasive and easily get to another person if one does not follow the rules of personal hygiene. One can get infected with pinworms in any food store where sanitary and hygienic standards are not observed. This is especially true for all suburban kebabs. 
If we use simple math, we can calculate how many eggs are released into the environment by one person infected with helminthiasis. A human female roundworm can produce 200 thousand eggs a day, and its life cycle lasts one year. This means that in 365 days, one person can release 73 million of roundworm eggs into the external environment. While the infection with ascariasis according to the data of The Federal Service for Surveillance on Consumer Rights Protection and Human Wellbeing in the city of Kemerovo is $19-20 \%$, with the prevalence of infection in the population in the South of Kuzbass, opisthorchiasis is more typical for residents of the northern part of the region and averages $12 \%$ from the Yurginsky to the Mariinsky districts.

The liver fluke produces up to 1 million eggs per year. Therefore, for 365 days, one patient with fascioliasis releases 730 thousand larvae per year. The last two representatives of helminths reproduce themselves asexually due to the fact that their life cycle at the larval stage takes place in an intermediate host. And, ultimately, at the stages of development, parasite species are lost under the influence of various factors encountered on the way of searching for a host.

We can emphasize that the production of a large number of eggs is reproduced by helminths with a simple life cycle (roundworm, pinworm). The release of a relatively small number of eggs into the external environment is typical for parasites with a complex life cycle (fasciola, opisthorchi, etc.). First, the eggs need to get into the water (river, artificial pond, lake), and then into the mallusk, etc. But in the intermediate host, a parthenogenetic generation of larvae is formed. And on wild lakes, which are numerous in Kuzbass, it is also possible to get infected with helminthiasis non-specific for humans - schistosomatid cercariae, which are brought by waterfowl birds during migration [12]. And here mathematical calculations of arriving birds is needed, you can always predict the probability of schistosoma drift.

It is no coincidence that mathematical, especially probabilistic, research methods are widely used in parasitology. These methods can be used with great success to analyze the nature and trends in the development of epidemic and epizootic processes. These data allow us to quantify the patterns underlying the phenomena of parasitism, establish numerical relationships between parasites and hosts, predict the dynamics of their abundance, and develop methods for landscape ecology. However, we must not forget that the mathematical interpretation of biological phenomena and the normal and pathological processes occurring in the body is associated with their schematization; it runs into great factual and methodological difficulties. Indeed, it is very difficult to isolate and quantify the role and impact of all factors influencing the development of parasitic processes. In addition, it is very difficult and almost impossible to reliably take into account all numerous variables that the biological system "parasite - host - external environment" includes, on the one hand, and which, on the other hand, are associated with the active human influence on this system.

So, there are natural factors for the spread of helminths in Kuzbass, but there are also significant biological factors, some of them should be necessarily taken into account. These are high fertility of helminths, both at larval and sexually mature stages of the life cycle; the presence of a sufficient number of parasite and host populations; the ability of the parasite to adapt to the changing biogeocenosis and life preservation in it.

For helminths that are pathogens of natural focal helminthiases, such as opisthorchiasis, other factors are also important: the presence of various species of mollusks, which are the first intermediate host in the life cycle of the parasite; a sufficient population of fish of the carp family in the reservoirs of the region.

As for the anthropogenic factor that contributes to the spread of helminthiases in the coal region, it is not compliance with the rules of personal hygiene and sanitary requirements. It should include: eating fish and meat that has not passed a sanitary and 
veterinary testing; eating raw fish and meat such as stroganina; using water for drinking from lakes and rivers without boiling or filtering; swimming in places where this is prohibited. It is important to observe sanitary standards in the urban planning of buildings or suburban houses in mountainous and hilly areas. This is especially true for outbuildings for keeping and breeding livestock and toilets. At the same time, it is necessary for the administrative and economic authorities of the city or district when distributing land plots to the population to check compliance with the norms of construction of The State Standards for the private sector, to conduct explanatory work with the population when organizing new objects under construction. This is the influence of the anthropogenic factor which combines personal and public prevention of the spread of helminthiases.

According to the authors, for the effective functioning of mineral resource clusters with a single-industry focus, it is necessary to form an ecological and economic mechanism that ensures the sustainable development of the mining regions of the Russian Federation in changing external and internal conditions that determine the functioning of not only the mineral resource complex of mining regions, but also its socio-economic development [13, 14]. Structurally, an action program to reduce the spread of helminthiases in Kuzbass can be an integral part of this mechanism. To do this, we strongly recommend the following activities: identification and treatment of patients with the mandatory analysis on helminths at prophylactic medical examinations and admission of patients for treatment; parasitological monitoring of children's institutions, promotion of sanitary-educational work through using the modern media (TV, radio, newspapers, posters); testing of fish and meat at the markets and shops of Kuzbass for the infestation with the larvae of parasitic worms; increasing levels of precision (reliability, and verification) of laboratory diagnostics with systematic training of laboratory assistants; trapping of stray cats that spread eggs of the opisthorchiasis pathogen, and dogs that infect the human environment with toxocars.

Special attention needs to be paid to the current situation related to the movement of people, and therefore it is necessary to conduct a strict control and sanitary checks of persons entering Kuzbass for study, work, and migrants. Most of the students who come to study from India and Egypt require additional examination. This is important for the formation of a healthy lifestyle of students and their psychological comfort $[15,16]$. In addition, it is necessary to systematically implement and improve the entire complex of epidemiological, organizational, methodological, therapeutic and preventive measures for the whole coal region.

\section{Conclusions}

The systematic organization of live nature in the structural and functional subordination of all ecological systems of various structural rank and structural level, combined in a complex and global system - the ecosphere, can give a high result in reducing the spread of helminthiases in the Kuzbass.

In the study the thesis is proved that for the effective functioning of such mineral-raw clusters with single-industry focus, as Kuzbass, the formation of ecological-economic mechanism is needed for sustainable development of the mining regions of the Russian Federation in the changing internal and external conditions that govern the functioning not only of the mineral complex of the mining regions, but also their socio-economic development.

The authors have developed and proposed practical measures for decreasing the incidence of helminthiases in the Kuzbass region, aimed at identification and treatment of patients at medical prophylactic examinations and admission of patients for treatment; carrying out checks for the presence of parasitosis in children's institutions; promotion of sanitary-educational work; conducting continuous testing of meat and fish coming to the 
markets and shops of Kuzbass for the infestation of the larvae of the parasites; improving laboratory diagnosis and increasing the skill level of laboratory staff, etc. It is the system approach that is of fundamental importance solving such interdisciplinary problems of helminthiases spread in the coal region. Only the symbiosis of medicine, economics, and ecology will reduce the severity and effectively solve this problem, since integrative orientation is one of the main functions of improving the system of human life and the basic support of the modern style of ecological thinking on a global scale.

\section{References}

1. D.G. Verzhitsky, V.A. Bezgubov, E.N. Starchenko, S.N. Chasovnikov, Fundamental research, 6:3, 560 (2015)

2. Yu. A. Stepanov, S. N. Chasovnikov, T. V. Korchagina, Bulletin of Kuzbass State Technical University, 2, 53 (2008)

3. S.N. Chasovnikov, Bulletin of TSPU, Series Natural and Exact Sciences, 6, 67 (2007)

4. V.M. Pitulko, V.V. Kulibaba, Assessment of opportunities for ecological rehabilitation of the Kemerovo region. Renovation of natural systems and elimination of objects of past environmental damage (Infra-M, Moscow 2018)

5. E.Yu. Balayan, Scientific Notes of the V. I. Vernadsky Crimean Federal University. Legal sciences, 4:70, 176-190 (2018)

6. L.V. Nacheva, R.M. Akbaev, Host organism as a parasite's life environment. Proceedings of IV International Scientific and Practical Conference, (Kemerovo, 2021).

7. I.N. Zavyrylina, N.A. Barbarash, L.V. Nacheva, Complex problems of cardiovascular diseases, 2, 60-63 (2012)

8. L.V. Nacheva, M.V. Dodonov, T E. Starchenkova, Opisthorchiasis in Kuzbass. Proceedings of the All-Russian scientific conference Theoretical and Practical Issues of Parasitology, (Kemerovo, 2006)

9. L.V. Nacheva, Anthropogenic factor in the spread of infectious and invasive diseases. Medico-biological problems of disease prevention in the Kuzbass industrial region (Kemerovo, 1995)

10. L.V. Nacheva, E.A. Sumbayev, F.A. Korsakov, Micromorphological features of studies of mollusks from anthropogenic reservoirs of Kemerovo infected with trematode larvae (the Republic of Kazakhstan, 2011)

11. L.V. Nacheva, M.G. Stepanova, Ecological features of an artificial reservoir in an urban area that ensure the development of small pond fish and their infection with miracidia fasciola (Kemerovo, 2019)

12. L.V. Nacheva, M.G. Stepanova, E.A. Sumbaev, On the possibility of human infection with schistosomatid cercariae in lakes and reservoirs with waterfowl birds (Kemerovo, 2019)

13. I. Kudryashova, M. Venger, N. Zakharova, E3S Web Conf. 105, 02005 (2019)

14. I. Kudryashova, K. Korsakov, E3S Web Conf., 105, 04020 (2019)

15. G.V. Akimenko, L.V. Nacheva, Science Diary, 8:32, 21 (2019)

16. V. B. Batievskaya, Bulletin of the Altai Academy of Economics and Law, 3:2, 15-27 (2019) 